\title{
Understanding Academic Performance based on Gender, Race, Stress and Sleep Quality
}

\author{
EUGENIE MOK YEN LING, TAN KOCK WAH* \\ Faculty of Cognitive Science \& Human Development, University Malaysia Sarawak (UNIMAS), Kota \\ Samarahan, 94300 Sarawak, Malaysia. \\ *Corresponding author: Tan Kock Wah (email: kwtan@unimas.my)
}

\begin{abstract}
This study aims to explore gender, race, stress and sleep quality as factors which influence the academic performance of undergraduate students. The samples of study involved 80 students from the Faculty of Cognitive Science and Human Development, Universiti Malaysia Sarawak. Questionnaire used in the data collection comprising demographic information, stress questionnaire (Student Stress Inventory (SSI)) and sleep quality questionnaire (Pittsburgh Sleep Quality Index (PSQI)). The academic performance of the undergraduate students in this study was measured by their cumulative grade point average (CGPA). The result of the study showed that female students performed better than male students; whilst non-Bumiputera students performed better than Bumiputera students. The study also found that the higher the stress level of a student (SSI score), the lower his or her CGPA results. Moreover, the findings showed that there is a significant difference in FCSHD undergraduates' academic performance based on their sleep quality, in which the mean of CGPA for students with good sleep quality is higher than that of students with bad sleep quality. Ultimately, the study reveals that gender and race do play a part in the academic performance of students and having good sleep quality and a little bit of stress is equally important in learning and helpful in attaining good grades and hence, should be leveraged by students.
\end{abstract}

Keywords: gender, race, stress, sleep quality, students, academic performance

Copyright: This is an open access article distributed under the terms of the CC-BY-NC-SA (Creative Commons Attribution-NonCommercial-ShareAlike 4.0 International License) which permit unrestricted use, distribution, and reproduction in any medium, for non-commercial purposes, provided the original work of the author(s) is properly cited

\section{INTRODUCTION}

University life is often deemed as one of the most stressful periods in a student's life. As students struggle to cope with exams, social pressures and future careers, many find themselves unable to deal with the situation. Some of them seek the easiest way out by ending their lives without thinking of the consequences. In a survey conducted by the American College Health Association (ACHA), it was reported that the suicide rate among young adults, whose age ranged between 15 to 24 years old, has tripled since the 1950s and currently, suicide is known to be the second most common cause of death among college students (Henriques, 2014).

In Malaysia, $7 \%$ of teenagers were reported to have suicide thoughts and the percentage of those who have turned the thoughts into actions were about half the percentage of those who have thought of committing suicide (Kok \& Goh, 2011). In a study by Mustaffa, Aziz, Mahmood and Shuib (2013), the statistics released by the National Suicide Registry Malaysia (NRSM) suggested that the number of suicides had peaked dramatically in the last three years (1,156 victims) whereas the national statistics showed that females' suicidal rate was higher than males by the ratio of 3:1. Hence, the rate of suicides was indeed alarming. There were many factors that lead to suicide including physical illness, unwillingness to seek help, isolation and feelings of hopelessness. Nonetheless, it is vital to understand that academic performance is also one of the factors that can lead to suicides among students. According to Regier (2015), academic success was vital due to it being closely linked to the positive outcomes we value. For instance, those who did well in their studies are more likely to get hired and less likely to get involved in criminal activity and were happier than those who did not do well academically. Moreover, students who performed better in school were better able to make the transition into adulthood and to achieve occupational and economic success. On the other hand, according to Lageborn, Ljung, Vaez and Dahlin (2017), low educational attainment was correlated with a higher risk of suicide. According to Sin Chew daily, a suicide case was reported which involved a female student from Tunku Abdul Rahman University College (TARUC). It was found that the pressure the student experienced from daily life and studies were too much for her to handle, hence these were the main reasons the suicide occurred (Kwan, 2017). 
Previous studies had been conducted to identify some of the factors that may have a huge impact on students' academic performance. According to Houston (2016), past research tend to focus more on factors such as personality traits, cognitive ability and motivational factors such as academic locus of control and self-efficacy which affect academic performance, however, little has been known whether demographic factors such as gender and race will have an impact on student's academic performance or not. Moreover, it is known that factors such as stress and sleep quality play a prominent role in determining students' academic performance, however the results obtained from past research were contradictory. Hence, this study aims to determine if there are differences in students' academic performance based on gender, race, stress and sleep quality respectively. This study will focus on undergraduates from the Faculty of Cognitive Sciences and Human Development, UNIMAS.

\section{Research Hypothesis}

\begin{tabular}{|l|l|l|}
\hline Test Performed & \multicolumn{2}{|c|}{ Null Hypothesis } \\
\hline Mann-Whitney U & $\mathrm{H}_{0} 1$ & $\begin{array}{l}\text { There is no significant difference in FCSHD undergraduates' academic } \\
\text { performance based on race. }\end{array}$ \\
\cline { 2 - 3 } & $\mathrm{H}_{0} 2$ & $\begin{array}{l}\text { There is no significant difference in FCSHD undergraduates' academic } \\
\text { performance based on gender. }\end{array}$ \\
\cline { 2 - 3 } & $\mathrm{H}_{0} 3$ & $\begin{array}{l}\text { There is no significant difference in FCSHD undergraduates' academic } \\
\text { performance based on sleep quality. }\end{array}$ \\
\hline $\begin{array}{l}\text { Spearman's } \\
\text { Correlation }\end{array}$ & $\mathrm{H}_{0} 4$ & $\begin{array}{l}\text { There is no relationship between stress and academic performance among } \\
\text { FCSHD undergraduates. }\end{array}$ \\
\hline
\end{tabular}

\section{MATERIALS \& METHODS}

This is a quantitative study with the aim to investigate the impact of gender, race, sleep quality and stress on academic performance. Convenience sampling technique was used to survey a sample of 80 students from the Faculty of Cognitive Science and Human Development (FCSHD), UNIMAS. The research instrument used in the data collection was questionnaire. The questionnaire consisted 3 sections where section A was concerned with collecting basic demographic information on gender, race and academic performance (CGPA), section B and section C comprised of stress questionnaire (Student Stress Inventory (SSI) and sleep quality questionnaire (Pittsburgh Sleep Quality Index (PSQI)) respectively.

The stress questionnaire consisted of 40 questions in which a Likert four points scale was used in the measurement where 1 corresponded to 'Never', 2 corresponded to 'Somewhat frequent', 3 corresponded to 'Frequent' and 4 corresponded to 'Always'. In terms of scoring, a total score of 40-80 meant mild stress, 81-121 meant moderate stress whereas 122-160 meant severe stress. On the other hand, the PSQI questionnaire consisted of 19 self-rated questions, taking into consideration the seven components which were subjective sleep quality, sleep latency, sleep duration, habitual sleep efficiency, sleep disturbances, use of sleeping medications, and daytime dysfunction over the last month where each component scores were weighted equally on a 0-3 scale, with 3 indicating the greatest dysfunction. The seven component scores were totalled to obtain a global PSQI score, ranging from 0-21. Participants who scored above 5 indicated that they had poor sleep quality whereas participants who scored 5 and below were considered to have good sleep quality. The SSI questionnaire was obtained from the Faculty of Education and Human Development, Sultan Idris Education University (Arip, 2016) whereas PSQI questionnaire was obtained from the Sleep and Chronobiology Center, Department of Psychiatry, University of Pittsburgh (Buysse, Reynolds III, Monk, Berman and Kupfer, 1988).

The questionnaires were pre-tested on a sample of 30 students to test the data-gathering mechanisms and to assess the validity and reliability of the questionnaire and the Cronbach's Alphas obtained for both Student Stress Inventory (SSI) and Pittsburgh Sleep Quality Index (PSQI) were 0.832 and 0.827 respectively. Moreover, students' self-reported Cumulative Grade Points Average (CGPA) were used to measure academic performance. Statistical Package for the Social Sciences (SPSS) would then be used to analyse the data collected. 


\section{RESULTS AND DISCUSSIONS}

\section{$H_{0}$ 1: There is no significant difference in FCSHD undergraduates' academic performance based on race.}

Table 1. Mean rank of academic performance (CGPA) based on race

\begin{tabular}{ccc}
\hline & \multicolumn{2}{c}{ Academic Performance (CGPA) } \\
\cline { 2 - 3 } & $\mathbf{N}$ & Mean Rank \\
\hline Bumiputera & 27 & 28.17 \\
Non-Bumiputera & 53 & 46.78 \\
\hline
\end{tabular}

Table 2. Mann-Whitney U test

\begin{tabular}{cccc}
\hline & \multicolumn{3}{c}{ Academic Performance (CGPA) } \\
\cline { 2 - 4 } & $\mathbf{Z}$ & $\mathbf{U}$ & Sig. (2-tailed) \\
\hline Race & -3.390 & 382.5 & 0.001 \\
\hline
\end{tabular}

A Kolmogrov-Sminov test indicated that the CGPA performances for the two groups did not follow a normal distribution. As such, a non-parametric test was performed. Based on Table 2, Mann-Whitney test indicated that the test was statistically significant in which the CGPA was greater for Non-Bumiputra (Mean Rank=46.78) than for Bumiputra (Mean Rank=28.17), $\mathrm{U}=382.5, \mathrm{p}=0.001$. Hence, $H_{01}$ was rejected.

Similar result was shown in a study by Tang and Daneil (2017), in which their findings indicated there was a significant difference in the mean CGPA among different races of students. Thus, the findings of this study indicated non-Bumiputera students performed better than Bumiputera students academically. Moreover, findings from studies in Western countries indicated there was a correlation between academic performance and race. In a study by Battle and Lewis (2008), African Americans was found to exhibit lower educational achievement. In another study by Che Azmi and Harith (2012), it was found that non-Bumiputera Malaysians performed academically better than Bumiputera Malaysians. Hence, by exploring the cultural backgrounds of different races when it comes to academic performance, educators will be more sensitive in terms of teaching as they are able to explore the needs of students of different races.

\section{$\mathrm{H}_{0}$ 2: There is no significant difference in FCSHD undergraduates' academic performance based on gender.}

Table 3. Mean rank of academic performance (CGPA) based on gender

\begin{tabular}{ccc}
\hline & \multicolumn{2}{c}{ Academic Performance (CGPA) } \\
\cline { 2 - 3 } & $\mathbf{N}$ & Mean Rank \\
\hline Male & 40 & 34.79 \\
Female & 40 & 46.21 \\
\hline
\end{tabular}

Table 4. Mann-Whitney U test

\begin{tabular}{cccc}
\hline & \multicolumn{3}{c}{ Academic } \\
& $\mathbf{Z}$ & $\mathbf{U}$ & Sig. (2-tailed) \\
\hline Gender & -2.2 & 571.5 & 0.028 \\
\hline
\end{tabular}

A Kolmogrov-Sminov test suggested that the CGPA did not follow a normal distribution for the two groups. Hence, a non-parametric test was performed. Based on Table 4, the Mann-Whitney test indicated that there was a statistically significant difference in CGPA between gender. The CGPA was greater for Female (Mean Rank=46.21) compared to Male (Mean Rank=34.79), $\mathrm{U}=571.5, \mathrm{p}=0.028$. Hence, $H_{02}$ was rejected.

The result was in line with the findings by Dayioğlu and Türüt-Aşik (2007) who reported that gender played a role in determining the academic performance of students and found that females performed better than males in 
higher education in terms of their CGPA. Besides, similar result was shown in a study by Khwaileh and Zaza (2010) where females tend to do better academically than males. This could be explained by Gnaulati (2014) where it was found that girls had far better self-regulation than boys and self-regulation was important when it came to academic performances. This, however, was in contrast with the result obtained from Leander (2016) where it was reported that male students outperformed females in exams and one of the possible explanations may be due to the way the exams were designed rather than students' academic ability. Nonetheless, generally, Voyer and Voyer (2014) speculated that social and cultural factors could be a possible explanation why females performed better than males academically. Hence, this study provided evidence that gender influenced academic performance of students and this was largely supported by past studies discussed in this paper.

$\mathrm{H}_{0}$ 3: There is no significant difference in FCSHD undergraduates' academic performance based on their sleep quality.

Table 5. Mean rank of academic performance (CGPA) based on sleep quality

\begin{tabular}{ccc}
\hline & \multicolumn{2}{c}{ Academic Performance (CGPA) } \\
\cline { 2 - 3 } & $\mathbf{N}$ & Mean Rank \\
\hline Good Sleep Quality & 42 & 45.8 \\
Bad Sleep Quality & 38 & 34.6 \\
\hline
\end{tabular}

Table 6. Mann-Whitney U test

\begin{tabular}{|c|c|c|c|}
\hline & \multicolumn{3}{|c|}{ Academic Performance (CGPA) } \\
\hline & $\mathbf{Z}$ & $\mathbf{U}$ & Sig. (2-tailed) \\
\hline Sleep Quality & -2.145 & 575.5 & 0.032 \\
\hline
\end{tabular}

A Kolmogrov-Sminov test indicated that the CGPA performances did not follow a normal distribution. Hence, a non-parametric test was performed. Based on Table 6, it was found that the test was statistically significant. Hence, $\mathrm{H}_{03}$ was rejected. It appeared that students with Bad Sleep Quality tend to score lower compared to those who could sleep well (Good Sleep Quality Mean Rank=45.8, Bad Sleep Quality Mean Rank=34.6), U=575.5, p=0.032.

Thus, as opposed to Nihayah et al. (2011) findings which concluded that sleeping hours did not affect students' academic performance (CGPA), the result obtained highlighted the importance of students having good sleep quality as it would be beneficial in the improvement of their academic achievements. This result was consistent with Curcio et al. (2006), where it was found that students who had poor sleep quality had a lower academic performance and students who had a more regular sleep-wake pattern tend to have a higher CGPA. These findings were supported by another study conducted by Kelly, Kelly and Clanton (2001), where it was shown that students who slept approximately 6 hours or less had a lower academic performance compared to students who slept for 9 or more hours per night. Hence, insufficient amount of sleep appeared to have a great impact on students' academic performance. One of the reasons was because sleepiness caused problems with concentration and mood, which made it harder for students to stay awake in class. Hence, the inability to concentrate and think clearly was likely to lead to poor academic performance.

Thus, students with good sleep quality achieved better academically than students with bad sleep quality. In sum, the result of the study provided evidence that students having good sleep quality are more likely to improve their academic achievement as they are more focused and alert.

$\mathrm{H}_{0}$ 4: There is no relationship between stress and academic performance among FCSHD undergraduates.

Table 7. Spearman's correlation table

\begin{tabular}{lcc}
\hline \multicolumn{1}{c}{ Stress } & $\boldsymbol{r}_{\boldsymbol{s}}$ & Sig \\
\hline Academic Performance (CGPA) & -0.259 & 0.020 \\
\hline * Correlation is significant at the 0.05 level (2-tailed).
\end{tabular}

Based on the results in Table 7, the correlation coefficient, $r_{s}$ was -0.259 , meaning the higher the stress level of a student (SSI score), the lower his or her CGPA results. Since the significant value $p=0.020$ where $p<0.05$, thus 
$H_{04}$ is rejected. Therefore, there is a significant relationship between stress and academic performance among FCSHD undergraduates, $r_{s}=-0.259, \mathrm{~N}=80, \mathrm{p}=0.020$.

According to Akgun and Ciarrochi (2003), respondents with a severe stress level were noticed to obtain higher CGPA. However, the results obtained in this study showed otherwise, in which students who had higher stress level did not perform as good as those who had lower stress level in academic terms. Furthermore, in a study by Sloboda (1990), the results showed that stress led to a detrimental academic performance in university. In another study by Khan and Chaudary (2014), it was found that students of a public university experienced stress which resulted in their inability to meet academic goals, poor academic performances and continuous decline in grades. One possible explanation is that stress negatively impact on students' ability to concentrate. When a student was not able to focus and pay attention in his or her studies, the amount of information absorbed and stored in the memory would also decrease, leading to poor grades (Lumontod, 2017). Hence, this study provides evidence that stress had an impact on the academic performance of students. In all, this study provided some insights into how different stress levels could impact differently on students' achievements: exposure to a moderate level of stress could have the potential to push an individual to perform better but excessive stress could be detrimental.

\section{CONCLUSION}

In conclusion, findings from the research revealed that there wa a significant difference in FCSHD undergraduates' academic performance based on gender, where female students performed better than male students; whilst non-Bumiputera students performed better than Bumiputera students. The study also found that the higher the stress level of a student (SSI score), the lower his or her CGPA results. Moreover, the findings showed that there was a significant difference in FCSHD undergraduates' academic performance based on their sleep quality, in which the mean of CGPA for students with good sleep quality was higher than that of students with bad sleep quality. As student life revolved around academic related matters, therefore its importance should not be overlooked as low educational attainment was often associated with a higher risk of suicide. Thus, this study provided more insight for undergraduate students regarding the factors affecting academic performance where a lower stress level and good sleep quality could be important in achieving good grades.

\section{ACKNOWLEDGEMENTS}

We would like to thank all parties who had assisted in making this project possible, especially to the respondents who had volunteered to participate in the study

\section{REFERENCES}

Akgun, S. \& Ciarrochi J. (2003). Learned resourcefulness moderates the relationship between academic stress and academic performance. Educational Psychology, 23(3), 287-294.

Arip, M. (2016). Manual of Student Stress Inventory (SSI) development, validity and reliability of Student Stress Inventory (SSI). Retrieved from https://www.researchgate.net/publication/316662054_Manual_of_ Student_Stress_Inventory_SSI_Development_Validity_And_Reliability_of_Student_Stress_Inventory_SSI

Battle, J. \& Lewis, M. (2008). The increasing significance of class: The relative effects of race and socioeconomic status on academic achievement. Journal of Poverty, 6(2), 21-35.

Buysse, D. J., Reynolds III, C. F., Monk, T. H., Berman, S. R., \& Kupfer, D. J. (1988). The Pittsburgh Sleep Quality Index: A new instrument for psychiatric practice and research. Psychiatry Research, 28, 193-213.

Che Azmi, A., \& Harith, S. (2012). Higher order cognitive skills and performance of undergraduate students: Do these skills differ among Asian groups? Far East Journal of Psychology and Business, 9(3), 19-28.

Curcio, G., Ferraraa, M., \& Gennaro, L. D. (2006). Sleep loss, learning capacity and academic performance. Sleep Medicine Reviews, 10(5), 323-337.

Dayioğlu, M., \& Türüt-Aşik, S. (2007). Gender differences in academic performance in a large public university in Turkey. The International Journal of Higher Education and Educational Planning, 53(2), 255-277.

Gnaulati, E. (2014). Why girls tend to get better grades than boys do. Retrieved from https://www.theatlantic. com/education/archive/2014/09/why-girls-get-better-grades-than-boys-do/380318/

Henriques, G. (2014). The college student mental health crisis. Retrieved from https://www.psychologytoday. com/us/blog/theory-knowledge/201402/the-college-student-mental-health-crisis

Houston, D. C. (2016). Explaining race differences in academic performance: The role of perceived expectations and outcome valence. (Unpublished master's thesis) Winston-Salem State University, North Carolina, United States of America. 
Kelly, W. E., Kelly, K. E., \& Clanton, R. C. (2001). The relationship between sleep length and grade-point average among college students. College Student Journal, 35(1), 84-86.

Khan, A. M., \& Chaudary, A. M. (2014). Impact of stress among students of a public sector university. Journal of Research and Reflections in Education, 8(1), 48-54.

Khwaileh, F., \& Zaza, H. I. (2010). Gender differences in academic performance among undergraduates at the university of Jordan: Are they real or stereotyping? College Student Journal, 45, 633-648.

Kok, J. K., \& Goh, L. Y. (2011). Young people and suicide issue. Paper presented at International Conference on Humanities, Society and Culture, Singapore.

Kwan, L. (2017). 20-year-old TARUC student commits suicide due to stress from work and studies. Retrieved from https://www.worldofbuzz.com/20-year-old-taruc-student-commits-suicide-due-stress-work-studies/

Lageborn, C. T., Ljung, R., Vaez, M., \& Dahlin, M. (2017). Ongoing university studies and the risk of suicide: A register-based nationwide cohort study of 5 million young and middle-aged individuals in Sweden, 19932011. BMJ Journals, 7(3), 1-8.

Leander, S. (2016). Gender gap discovered in science-exam performance. Retrieved from https://asunow.asu. edu/20160602-gender-gap-discovered-science-exam-performance

Lumontod, R. (2017). The effect of stress on students' academic performance. Retrieved from https:// psychlens.com/effect-of-stress-on-students/

Mustaffa, S., Aziz, R., Mahmood, M. N., \& Shuib, S. (2013). Depression and suicidal ideation among university students. Journal of Social and Behavioural Sciences, 116, 4205-4208.

Nihayah, M., Ismarualyusda, I., Syarif, H. L., NurZakiah, M. S., Baharudin, O., \& Fadzil, M. H. (2011). Sleeping hours and academic achievements: A study among biomedical science students. Procedia Social and Behavioral Sciences, 18, 617-621.

Regier, J. (2015). Why is academic success important? Retrieved from https://saskschoolboards.ca/wpcontent/uploads/2015/08/2011 siast.pdf

Sloboda, J. A. (1990). Combating examination stress among university students: Action research in an institutional context. British Journal of Guidance \& Counselling, 18 (2), 124 - 136.

Tang, H. E., \& Daneil, I. L. (2017). Demographic background, gender and race: Their impacts on students' academic success. Pertanika Journal of Social Sciences and Humanities, 25, 105-114.

Voyer, D. \& Voyer, S. (2014). Gender differences in scholastic achievement: A meta-analysis. Psychological Bulletin, 140(4), 1174-1204. 